\title{
Katabatic wind influence on meltwater supply to fuel glacier-substrate interactions at the grounding line, Terra Nova Bay, East Antarctica
}

\author{
A. Bouzette, R. Souchez \\ Département des Sciences de la Terre et de l'Environnement, Faculté des Sciences, Université Libre de Bruxelles, B-1050 Brussels, Belgium
}

\begin{abstract}
The co-isotopic composition, both in $\delta \mathrm{D}$ and in $\delta^{18} \mathrm{O}$, of interbedded debris-rich and clear ice layers, thought to have been formed at the grounding line of Hells Gate Ice Shelf, indicates freezing by a double-diffusion effect between continental meltwater and sea water within a subglacial sediment. A source of meltwater is required to sustain the process, since the temperature of the bed is below the freshwater melting point. The most likely source is a surficially frozen meltwater lake.

Rock outcrops, kept mostly snow-free by the action of katabatic winds, absorb solar radiation so local production of liquid water becomes possible in an area with year-round subfreezing air-temperature conditions. The meltwater accumulated in a marginal lake can eventually reach the subglacial substratum near a pinning point where the ice is relatively thin and fractured.
\end{abstract}

\section{INTRODUCTION}

Freezing can occur at the grounding line in Terra Nova Bay, East Antarctica, by a double diffusion effect. If meltwater is present in a subglacial sediment and if sea water at its freezing temperature is seeping through this sediment where the glacier becomes afloat, then a peculiar thermodynamic situation exists. The respective freezing temperatures for the two waters are different because of a difference in salt content. Diffusion of heat is an order of magnitude higher than diffusion of salts. Heat will diffuse from meltwater to sea water, while salts will diffuse from sea water to fresh meltwater. Because of this difference in diffusion rates, freezing occurs and debris incorporation into the glacier is possible at the grounding line. The occurrence of such a process was indicated by Souchez and others $(1995,1998)$ for the Campbell Glacier Tongue. This paper investigates a similar situation in the Hells Gate Ice Shelf area and proposes a likely source for the basal meltwater required. A pinning point seems to play a major role within this context.

\section{SITE DESGRIPTION}

The Terra Nova Bay area is located in northern Victoria Land along the western margin of the Ross Sea. In its southern part, two important outlet glaciers, Priestley and Reeves Glaciers, both originating on the polar plateau near Talos Dome, meet to form the Nansen Ice Shelf. The small Hells Gate Ice Shelf (HGIS) is separated from the Nansen Ice Shelf by two pinning points: Vegetation Island at the north and Inexpressible Island to the south (Fig. 1). The ice nourishing this small ice shelf comes from the eastern part of Priestley Glacier and from the adjacent Browning Pass. The grounding line is thought to be near Black Ridge and recent information from an Italian traverse indicates that part of the ice coming from Browning Pass is floating (per- sonal communication from M. Frezzotti, 1996). The HGIS is at least partly grounded in the pass between Vegetation and Inexpressible Islands, as indicated by global-positioningsystem (GPS) measurements (Capra and others, 1996).

Strong katabatic winds from the polar plateau characterize both the Reeves and Priestley glacial troughs and are responsible for the existence of the Terra Nova Bay polynya.

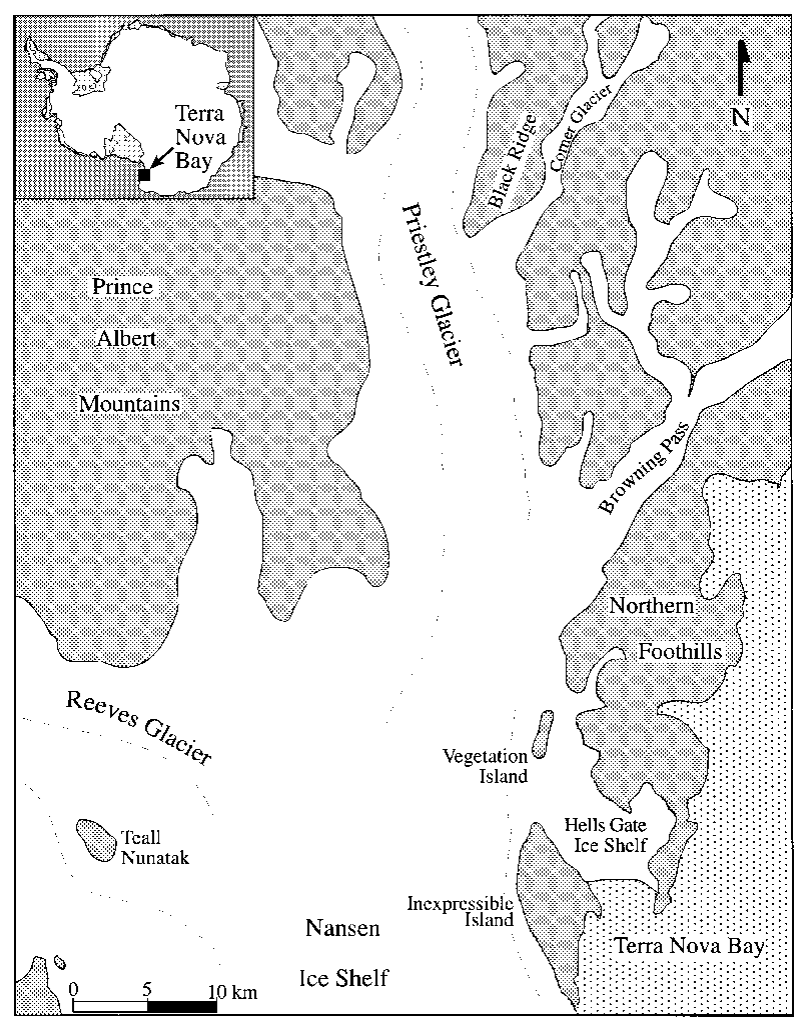

Fig. 1. Principal locations in the Terra Nova Bay area. 


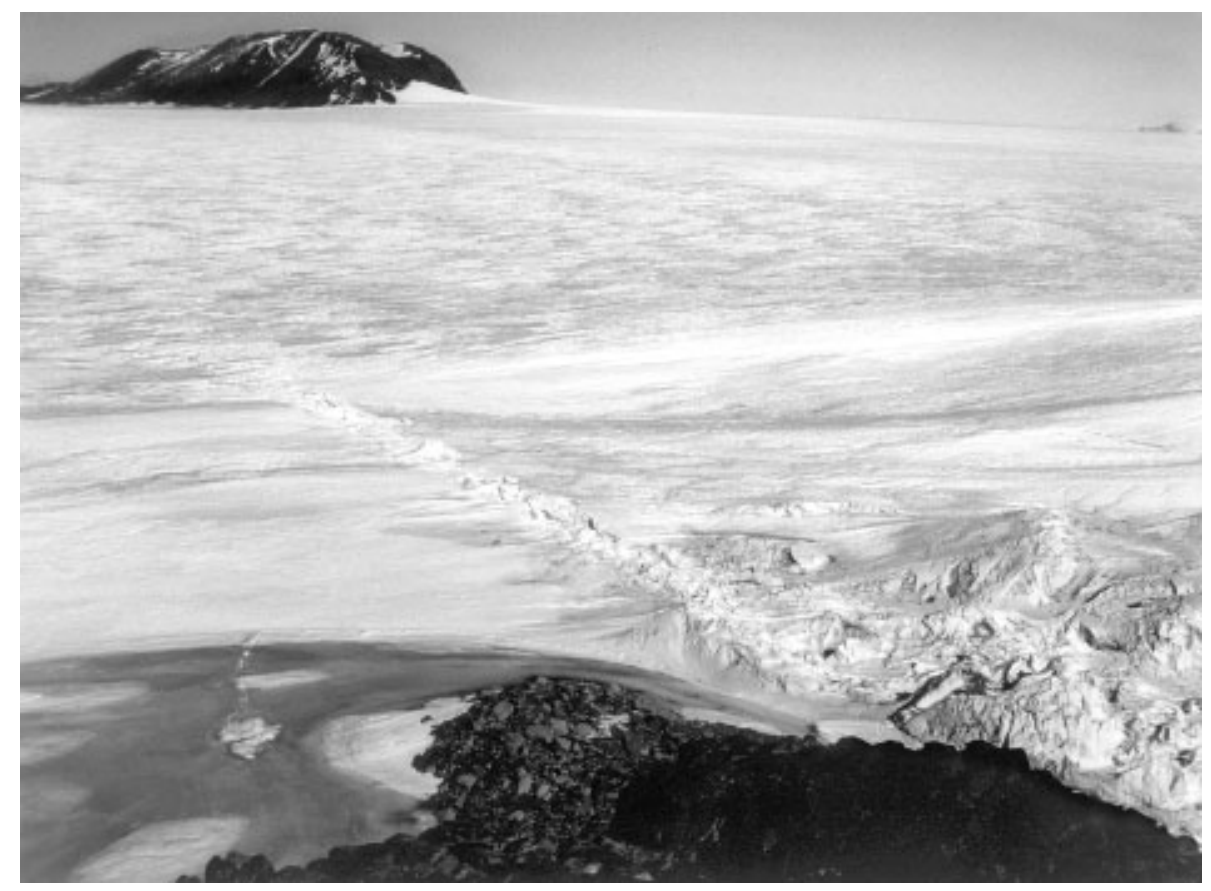

Fig. 2. View from the southern tip of Vegetation Island to Inexpressible Island (upper left) and across Nansen Ice Shelf to the Transantarctic Mountains (upper right). Note the meltwater lake around Vegetation Island draining through a "bédière" located upstream of a linear crevasse.

Snow-free areas, such as Black Ridge, the southern part of the Northern Foothills, Vegetation and Inexpressible Islands, are a consequence of the persistence of these winds. Katabatic winds are also responsible for the existence of blue-ice fields developed at the surface of these glaciers, e.g. in the Priestley linear trough, around Black Ridge, near Teall Nunatak along the Reeves Glacier and in the HGIS area.

Marginal lakes, surficially frozen, are developed between the glacier-ice surface and snow-free rock outcrops along the sides of the valley. Such lakes are well displayed, for example, near Black Ridge, Inexpressible Island and Vegetation Island (Fig. 2), in year-round subfreezing air-temperature conditions. These areas are affected by katabatic winds, as suggested by the presence of blue-ice fields nearby and by automatic weather-station records. Liquid water is usually present under a lake ice cover $1.5-2 \mathrm{~m}$ thick. Such lakes result from the local production of liquid water due to heat released from the absorption of solar radiation by rock. If the water collected during successive summers is deeper than the winter freezing front, then the lake can increase in size, eventually melting adjoining glacier ice. Ablation by katabatic winds is responsible for the bareness of the rock which is conducive to meltwater production. Hence names such as Black Ridge or Vegetation Island. Meltwater lakes also exist on the surface of HGIS, but only in its outer part near the sea. Such lakes are connected with outcroppings of marine ice .

HGIS is snow-free over most of its surface. Due to strong katabatic winds it has a high ablation rate and is losing ice, mostly by sublimation. Since surface ablation is prevalent, an upward velocity component exists and ice, initially at depth, is transferred along an inclined plane toward the ice-atmosphere interface down-glacier. This is why marine ice, accreted at the bottom, appears at the ice-shelf surface (Baroni and others, 1991b; Souchez and others, 1991; Tison and others, 1993, 1998). HGIS consists of three different sec- tors separated by ridges of debris cones. Only the western and central sectors will be considered here, since they are the only ones nourished by ice from the up-glacier drainage basin. They are separated from each other by a major shear zone including two ridges of debris cones containing rock fragments. Large-scale morphological patterns, marine-ice outcropping patterns and ice-foliation patterns suggest a complex dynamic behavior of converging flow (Tison and others, 1998). An oblique component of the flow into the western sector brings the ice into compression against the central sector.

\section{DEBRIS-RIGH ICE IN THE WESTERN MORAINE OF HGIS}

Boulders are frequent in the debris cover of the two debriscone ridges forming the western medial moraine of HGIS (Fig. 3). These boulders are supraglacial in origin and result from rockfall on the glacier surface in the upstream glacierized basin.

The debris cones, higher than the general glacier surface because of reduced ablation due to protection by debris, are, under a veneer of rock fragments, ice-cored with ice of various origins. Bubbly glacier ice, marine ice and interbedded debris-rich and clear ice layers with subvertical foliation can be distinguished. The interbedded debris-rich and clear ice layers are particularly rewarding to study. There is little doubt they have a subglacial origin since they sometimes contain shells, worm tubes (serpulids) and sponge spicules, also present in the marine ice. Hypothesizing that these biogenic materials were incorporated into the base of HGIS near the southern tip of Vegetation Island, Baroni (1990) and Baroni and others (1991a) estimated the surface velocity from their radiocarbon ages which increase in the down-glacier direction (Fig. 3). The velocities obtained $\left(10.4-17.4 \mathrm{ma}^{-1}\right)$ 


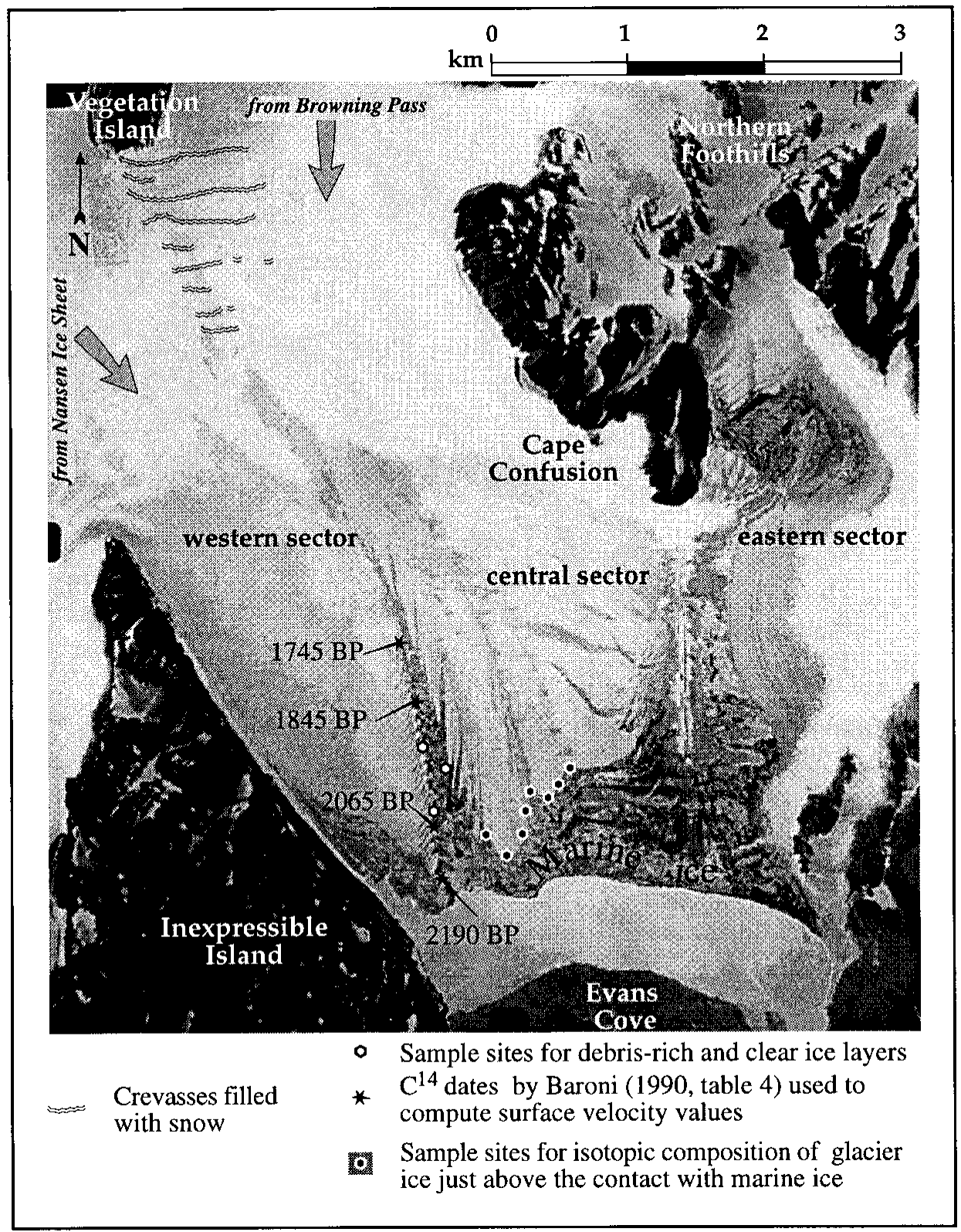

Fig. 3. Sample sites and main features of the Hells Gate Ice Shelf. Based on Terra Nova Bay aerial photograph (11 June 1985, FL 152.27, TMA-2851-V).

are in good agreement with those calculated by Frezzotti (1993) from comparison of aerial photographs taken in 1956 and $1985\left(8.8-11.9 \mathrm{~m} \mathrm{a}^{-1}\right)$.

Oxygen- and hydrogen-isotope compositions of the interbedded debris-rich and clear ice layers are very different from those of snow and glacier ice. The $\delta^{18} \mathrm{O}$ values of the snow collected at various sites in the area exhibit a good correlation (correlation coefficient $r=0.898 ; 16$ samples) with elevation. The equation derived is $\delta^{18} \mathrm{O}=-0.006 E-17.664$ with $E$ being the elevation in meters. The intersection of this straight line with $0 \mathrm{~m}$ elevation indicates that a snow sample is always more negative than $-17 \%$ in $\delta^{18} \mathrm{O}$. This is also true for glacier ice derived from such snowfall, since here the transformation process implies only a very limited quantity of liquid water. Souchez and others (1998) showed that glacier-ice samples from the same area are more negative than $-17 \%$ in $\delta^{18} \mathrm{O}$ and $-130 \%$ in $\delta \mathrm{D}$; they are aligned on a straight line in a $\delta \mathrm{D}-\delta^{18} \mathrm{O}$ diagram with equation $\delta \mathrm{D}=7.91$ $\delta^{18} \mathrm{O}+2.59(r=0.997 ; 55$ samples $)$ which can be considered as a precipitation line (local meteoric water line). Inter- bedded debris-rich and clear ice layers exhibit by contrast a large range of $\delta$ values between slightly negative values close to standard mean ocean water (SMOW) and $-20 \%$ in $\delta^{18} \mathrm{O}$ or $-160 \%$ in $\delta \mathrm{D}$. In a $\delta \mathrm{D}-\delta^{18} \mathrm{O}$ diagram, samples from these ice layers are well aligned on another straight line (Fig. 4) with equation $\delta \mathrm{D}=7.78 \delta^{18} \mathrm{O}-0.16(r=0.997 ; 8$ samples $)$. This last straight line is, however, not very different from the previous one on which glacier-ice samples are aligned in view of the confidence intervals on the regression lines. This line cannot be considered as a freezing slope which would have a much lower value for the angular coefficient (Jouzel and Souchez, 1982). The ice forming the interbedded debrisrich and clear ice layers cannot, however, be of direct glacial origin. Most of the samples have $\delta^{18} \mathrm{O}$ values much less negative than $-17 \%$, the limiting value for present-day snow or for glacier ice from the Holocene period. For this reason, altitude effects or differences in isotopic composition due to climatic changes cannot explain the distribution. Does the fact that no freezing slope is displayed on a $\delta \mathrm{D}-\delta^{18} \mathrm{O}$ diagram imply that no phase change from liquid water to ice 


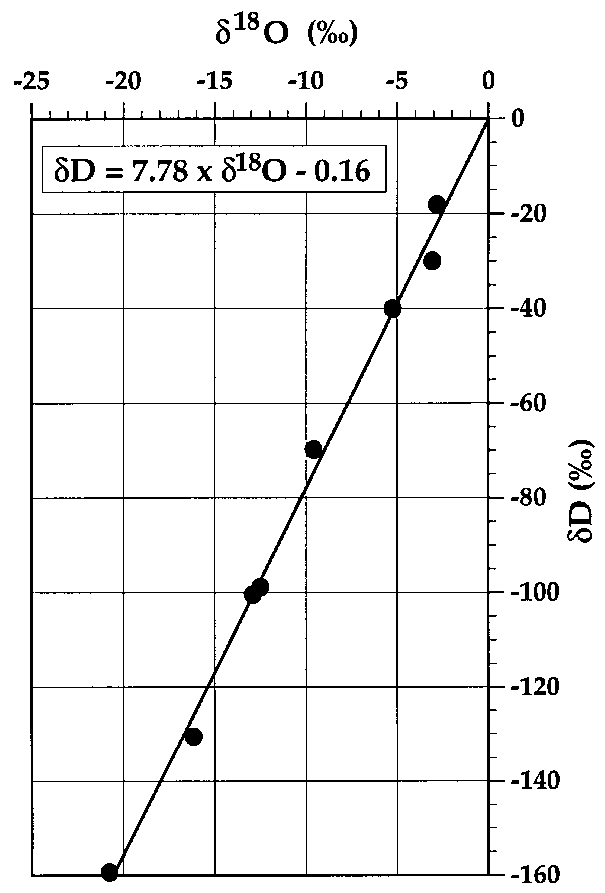

Fig. 4. $\delta D-\delta^{18} O$ relationship for interbedded debris-rich and clear ice layers from the western moraine of Hells Gate Ice Shelf.

occurred? Freezing is accompanied by an isotopic fractionation. Ice is enriched in heavy isotopes of oxygen and hydrogen compared to water. During freezing of a small finite reservoir, ice initially enriched in heavy isotopes can, however, become more negative than initial water in the course of the phase change, since residual water becomes more and more depleted in heavy isotopes. Therefore, depending on the sampling resolution, ice due to complete freezing of a limited water reservoir can have the same isotopic composition as the water before the phase change. This is in great contrast to the situation resulting from partial freezing. Another way of understanding the absence of a significant difference in isotopic composition between ice resulting from water freezing and initial water is by considering the freezing rate. If the freezing rate is high, ice and water will have the same $\delta$ value after a short initial transient (Souchez and Lorrain, 1991). Taking into account that freezing at the base of a glacier is a relatively slow process, occurring most probably close to isotopic equilibrium, such a situation is less probable.

From the considerations above, the large range in $\delta$ values exhibited by the interbedded debris-rich and clear ice layers cannot result from the distribution of samples along a freezing slope during phase change. It must therefore result from the large differences in isotopic composition of the waters filling the subglacial sediment prior to freezing. Now, the regression line (Fig. 4) passes close to the point representing mean sea water in the area (mean $\delta$ values for sea water in front of HGIS are $-0.6 \%$ in $\delta^{18} \mathrm{O}$ and $-4.0 \%$ in $\delta \mathrm{D}$ (Souchez and others, 1991) and the least negative sample of the interbedded debris-rich and clear ice layers is only slightly more negative than local sea water. Such characteristics of the isotopic composition of the interbedded debrisrich and clear ice layers from HGIS are consistent with the double-diffusion freezing mechanism described in the introduction. If glacier-ice meltwater within the subglacial sediment contacts sea water seeping through this sediment at the grounding line (or around a pinning point), diffusion will occur. Like salts, heavy isotopes of oxygen and hydrogen will diffuse from sea water (where they are less impoverished) to continental meltwater (where they are more depleted). Diffusion coefficients of stable isotopes and of salts in liquid water have the same order of magnitude, so the double-diffusion mechanism leads also to isotopic diffusion. The isotopic composition of the interbedded debris-rich and clear ice layers thought to be formed by freezing at the grounding line is thus dependent on the magnitude of the diffusion process prior to complete freezing for each increment. Once the ice is formed, the different isotopes of oxygen and hydrogen are within the ice lattice and only subjected, on very long time-scales, to solid-state diffusion. The straight line on which the interbedded debris-rich and clear ice layers are aligned in a $\delta \mathrm{D}-\delta^{18} \mathrm{O}$ diagram (Fig. 4 ) is thus the consequence of a diffusion process taking place before freezing.

\section{SUBGLAGIAL MELTWATER ORIGIN}

The isotopic composition of the continental meltwater at the origin of the double-diffusion mechanism can be estimated in the following way. The intersection point between the diffusion-line equation $\left(\delta \mathrm{D}=7.78 \delta^{18} \mathrm{O}-0.16\right)$ and the precipitation line on which glacier-ice samples are aligned $(\delta \mathrm{D}=$ $\left.7.91 \delta^{18} \mathrm{O}+2.59\right)$ has $\delta \mathrm{D}=-164.7 \%$ and $\delta^{18} \mathrm{O}=-21.15 \%$. Such $\delta$ values should represent both the composition of the lake meltwater and of the ice resulting from freezing of this water, if complete freezing occurred for each increment. Indeed, in that case, as discussed above, there is no difference in isotopic composition between ice and water. It should be noted that, if equilibrium fractionation had occurred, reconstruction of the regression line through the parent water for the ice samples would give a $\delta^{18} \mathrm{O}$ value of $-0.96 \%$ for the intersection point with the precipitation line. This is clearly not possible since continental snow or ice never has such a high $\delta$ value and since ice samples with $\delta$ values ranging from $-17 \%$ to $-0.96 \%$ cannot result from freezing of a mixture of sea water and fresh meltwater at -0.96 . As indicated above, the $\delta$ values of the intersection point should, however, be taken with caution in view of the confidence intervals for the regression lines. Are such $\delta$ values compatible with those existing in basal glacier ice near the pinning point? The isotopic composition of ice at the base of HGIS in the central sector close to the pinning point can be appraised in the following way. As a consequence of the upward velocity component, the contact between glacier ice and marine ice accreted at the bottom of the ice shelf can be traced at the ice-shelf surface. The ice just above the contact was previously at depth, presumably close to the base. The possibility that melting occurs at the ice-ocean interface when the glacier becomes afloat and prior to the formation of marine ice at the bottom cannot be excluded. It is, however, considered insignificant in view of the suggested position of the grounding area and the ice velocity. Moreover, the radiocarbon dates obtained by Baroni (1990) on the biogenic material thought to be incorporated near the southern tip of Vegetation Island suggest that marine ice is formed as soon as the ice around the island becomes afloat. Furthermore, high-salinity shelf water which would be responsible for basal melting is not present at such depths in this location (Tison and others, 1998). Glacier ice, previously at the base of HGIS near the grounding area, can thus easily 
be sampled at the ice-shelf surface, along the line separating ice of continental origin from marine ice (black dots in Fig. 3). Results of the isotopic analyses indicate $\delta^{18} \mathrm{O}$ values clustering around $-23 \%$ to $-26 \%$ ) with one value reaching $-30 \%$. Meltwater produced by geothermal and frictional heat at the glacier base has an isotopic composition similar to that of the ice at the glacier-substratum interface since there is no fractionation on ice melting (Moser and Stichler, 1980). Is such water the meltwater required for the double-diffusion freezing mechanism occurring at the grounding line? The similarity of $\delta^{18} \mathrm{O}$ values between those of the intersection point and of ice at the base of HGIS in the central sector close to the pinning point is not a decisive argument for the origin of the meltwater. Indeed, the thickness of the ice between Vegetation Island and the Northern Foothills, the main feeder for the central sector of HGIS, is estimated to be as much as $250 \mathrm{~m}$ by radio-echo sounding (Tison and others, 1998). Considering the mean surface air temperature in the area is about $-18^{\circ} \mathrm{C}$, calculations based on Hooke's method (1998) indicate that the pressure-melting point is not reached at the bottom $\left(-9.5^{\circ} \mathrm{C}\right.$ if horizontal advection is ignored). It is thus unlikely that substantial meltwater could be produced at the ice--bedrock interface by geothermal and frictional heat to sustain the double-diffusion freezing mechanism responsible for the formation of debris-rich ice layers of the western moraine. Is there another possible source of water?

Meltwater accumulated in marginal lakes may eventually reach the subglacial substrate. A meltwater lake exists near the southern tip of Vegetation Island. A small outlet stream from this lake is disappearing into the ice. At this place the ice is relatively thin, a few tens of meters. The water from this stream has an isotopic composition of about $-24 \%$ in $\delta^{18} \mathrm{O}$. We believe that water from the southern tip of Vegetation Island is the source of the meltwater required for the double-diffusion freezing mechanism. The thinness of the glacier ice and the presence of crevasses (Fig. 2) near the pinning point are important elements to consider. In certain circumstances they allow meltwater to reach the subglacial substratum. The suggested mechanism is in accordance with the radiocarbon dates obtained by Baroni (1990), which increase in age in a down-glacier direction (Fig. 3).

\section{GONGLUSION}

A double-diffusion freezing mechanism, responsible for rock fragments and biogenic material incorporation at the grounding line, is operating at a pinning point due to favourable circumstances. The glacier being cold throughout, meltwater in sufficient quantity to sustain the process can- not be produced by geothermal and frictional heat. A marginal lake, surficially frozen due to katabatic winds, can supply such meltwater in an area of relatively thin and fractured ice. The later appearance of the subglacial debris at the surface of HGIS is a consequence of ablation and of the resulting upward velocity component of the ice.

\section{AGKNOWLEDGEMENTS}

This paper is a contribution to the Belgian Antarctic Programme (Science Policy Office). R. S. thanks the Italian Programma Nazionale di Richerche in Antartide for the invitation to work at Terra Nova Bay in 1989-90.

\section{REFERENCES}

Baroni, C. 1990. The Hells Gate and Backstairs Passage ice shelves (Victoria Land, Antarctica). Mem. Soc. Geol. Ital., 43, 1988, 123-144.

Baroni, C., M. Frezzotti, C. Giraudi and G. Orombelli. 1991a. Ice flow and surficial variation inferred from satellite image and aerial photograph analysis of Larsen ice tongue, Hells Gate and Nansen ice shelves (Victoria Land, Antarctica). Mem. Soc. Geol. Ital., 46, 69-80.

Baroni, C., B. Stenni and P. Iacumin. 1991b. Oxygen isotopic composition of ice samples from the Hells Gate and Backstairs Passage ice shelves (Victoria Land, Antarctica): evidence of bottom freezing. Mem. Soc. Geol. Ital., 46, 45-48.

Capra, A., F. Radicioni and L. Vittuari. 1996. Kinematic GPS profiles and navigation in Antarctica. Int. Arch. Photogramm. Remote Sensing, 31 (B1), $31-35$.

Frezzotti, M. 1993. Glaciological study in Terra Nova Bay, Antarctica, inferred from remote sensing analysis. Ann. Glaciol., 17, 63-71.

Hooke, R. LeB. 1998. Principles of glacier mechanics. Upper Saddle River, NJ, Prentice Hall.

Jouzel, J. and R. A. Souchez. 1982. Melting-refreezing at the glacier sole and the isotopic composition of the ice. F. Glaciol., 28(98), 35-42.

Moser, H. and W. Stichler. 1980. Environmental isotopes in ice and snow. In Fritz, P. and J. C. Fonte, eds. Handbook of environmental isotope geochemistry. Vol. 1. The terrestrial environment. Amsterdam, Elsevier Publishing Co., 141-178.

Souchez, R.A. and R. D. Lorrain. 1991. Ice composition and glacier dynamics. New York, etc., Springer-Verlag. (Springer Series in Physical Environment 8.)

Souchez, R. and 7 others. 1991. Ice composition evidence of marine ice transfer along the bottom of a small Antarctic ice shelf. Geophys. Res. Lett., 18(5), 849-852.

Souchez, R. and 6 others. 1995. Investigating processes of marine ice formation in a floating ice tongue by a high-resolution isotopic study. F. Geophys. Res., 100 (C4), 7019-7025.

Souchez, R., A. Khazendar, D. Ronveaux and J.-L. Tison. 1998. Freezing at the grounding line in East Antarctica: possible implications for sediment export efficiency. Ann. Glaciol., 27, 316-320.

Tison, J. L., D. Ronveaux and R. D. Lorrain. 1993. Low salinity frazil ice generation at the base of a small Antarctic ice shelf. Antarct. Sci., 5(3), 309-322.

Tison, J.-L., R. D. Lorrain, A. Bouzette, M. Dini, A. Bondesan and M. Stiévenard. 1998. Linking landfast sea ice variability to marine ice accretion at Hells Gate Ice Shelf, Ross Sea. In Jeffries, M. O., ed. Antarctic sea ice: physical processes, interactions and variability. Washington, DC, American Geophysical Union, 375-407. (Antarctic Research Series 74.) 